\title{
Passivation Behavior of a Zr60Cu20Ni8A17Hf3Ti2 Bulk Metallic Glass in Sulfuric Acid Solutions
}

\author{
Junlei Tang ${ }^{1,2}$, Yingying Wang ${ }^{1, *}$, Qiuhong Zhu ${ }^{1}$, Mohamad Chamas ${ }^{1}$, Hu Wang ${ }^{3}$, \\ Jichao Qiao ${ }^{4}$, Yuanqiang Zhu ${ }^{1}$ and Bernard Normand ${ }^{5}$ \\ ${ }^{1}$ College of Chemistry and Chemical Engineering, Southwest Petroleum University, Chengdu 610500, \\ China; \\ ${ }^{2}$ State Key Laboratory of Oil and Gas Reservoir Geology and Exploitation, Southwest Petroleum \\ University, Chengdu 610500, China; \\ ${ }^{3}$ College of Material Science and Engineering, Southwest Petroleum University, Chengdu 610500, \\ China; \\ ${ }^{4}$ School of Mechanics, Civil Engineering and Architecture, Northwestern Polytechnical University, \\ Xi' an 710072, China; \\ ${ }^{5}$ Université de Lyon, INSA de Lyon, MATEIS CNRS UMR 5510, Villeurbanne 69621, France; \\ *E-mail: yingyingwanglyon@ 126.com
}

doi: $10.20964 / 2018.07 .17$

Received: 24 March 2018 / Accepted: 3 May 2018 / Published: 5 June 2018

The passivation behavior of $\mathrm{Zr}_{60} \mathrm{Cu}_{20} \mathrm{Ni}_{8} \mathrm{Al}_{7} \mathrm{Hf}_{3} \mathrm{Ti}_{2}$ bulk metallic glass (BMG) in $\mathrm{H}_{2} \mathrm{SO}_{4}$ solutions were studied by electrochemical measurements and $\mathrm{X}$-ray photoelectron spectroscopy. The influence of $\mathrm{H}_{2} \mathrm{SO}_{4}$ solutions concentration and temperature, heat treatment temperature and erosion on passivation behavior were analyzed. The corrosion resistance of $\mathrm{Zr}_{60} \mathrm{Cu}_{20} \mathrm{Ni}_{8} \mathrm{Al}_{7} \mathrm{Hf}_{3} \mathrm{Ti}_{2}$ bulk metallic glass decreases slightly with the increase of concentration and temperature of $\mathrm{H}_{2} \mathrm{SO}_{4}$ solutions. The $\mathrm{Zr}$-based BMG exhibits excellent passivation ability in various $\mathrm{H}_{2} \mathrm{SO}_{4}$ solutions. The formed passive films in $\mathrm{H}_{2} \mathrm{SO}_{4}$ solutions possess the semiconductor characteristics depending of applied potential, and show ntype semiconductor in stable passivation region. The main component of passive films is $\mathrm{ZrO}_{2}$ in competition with $\mathrm{HfO}_{2}$ and $\mathrm{Al}_{2} \mathrm{O}_{3}$, and no $\mathrm{Ni}$ element, and the alloy surface whose passive film contains less $\mathrm{Cu}$ and more $\mathrm{Al}_{2} \mathrm{O}_{3}$ and less $\mathrm{Cu}$, hence the alloy exhibits can have better corrosion resistance. Annealing which temperatures are lower than $\mathrm{T}_{\mathrm{g}}$ were conducted. After the heat treatment, Zr-based BMG maintains amorphous structure, and the electrochemical behavior of Zr-based BMG does not show obvious difference. However, the heat treatment improves BMG' micro-hardness. Consequently, the $\mathrm{Zr}$-based BMG after heat treatment has stronger erosion-corrosion resistance than the as-cast BGM.

Keywords: Bulk metallic glass; Corrosion resistance; Passive films; Heat treatment; XPS analysis; corrosion-eorsion 


\section{FULL TEXT}

(C) 2018 The Authors. Published by ESG (www.electrochemsci.org). This article is an open access article distributed under the terms and conditions of the Creative Commons Attribution license (http://creativecommons.org/licenses/by/4.0/). 